\title{
A MIDDLE-AGED FEMALE WITH FACTITIOUS DISORDER PRESENTING AS PARKINSONISM AND DEPRESSION- A CASE REPORT
}

\author{
Bhuvana C. Revappala1, Jaya Bharathi², Revathi K. Gowda ${ }^{3}$ \\ ${ }^{1}$ Consultant Psychiatrist, Wellspring Mind Care, Sharavathinagara, Shimoga. \\ ${ }^{2}$ Psychologist, Wellspring Mind Care, Sharavathinagara, Shimoga. \\ ${ }^{3}$ Assistant Doctor, Wellspring Mind Care, Sharavathinagara, Shimoga.
}

\begin{abstract}
BACKGROUND

A 52 years old female presented with the complaints of slowness of all voluntary movements, weakness, dizziness, constipation, urinary incontinence, etc. from the past 5 years. She was diagnosed of having Parkinson's disorder by the neurologists, was advised anti-Parkinson's drugs. She had undergone several investigations, requesting for various other procedures and consulted various neurologists and specialists including psychiatrists who diagnosed it as Parkinson's with co-morbid depressive disorder based on her feigning symptoms. But she claims no improvement in any of her symptoms with medications. Her inconsistent clinical picture and symptoms that do not respond to the seemingly appropriate treatment alert the psychiatrist about the possibility of having factitious disorder with co-existing other psychiatric disorder. These misleading informations and manipulative behaviours make her illness to become chronic with poor prognosis. In this case report, a middle-aged woman who is factitiously presented as Parkinson's and depressive symptoms is going to be presented which is a very interesting and challenging case.
\end{abstract}

\section{KEYWORDS}

Factitious Disorder, Parkinson's Symptoms, Depressive Disorder, Personality Disorder, Bradykinesia.

HOW TO CITE THIS ARTICLE: Revappala BC, Bharathi J, Gowda RK. A middle-aged female with factitious disorder presenting as Parkinsonism and depression - case report. J. Evolution Med. Dent. Sci. 2016;5(98):7219-7221, DOI: 10.14260/jemds/2016/1633

\section{BACKGROUND}

Factitious disorders represent one of the most disturbing, bewildering and frustrating presentations in psychiatric or medical practice. Factitious disorder is characterised by intentional feigning of physical signs and symptoms, can include any system of the body including neurological symptoms or psychological signs and symptoms can be any form of psychiatric illness usually depression, anxiety and rarely psychotic symptoms. ${ }^{1}$

The best known type of factitious disorder, Munchausen syndrome, is marked by a chronic unremitting course with repeated hospitalisations. ${ }^{2}$ Factitious disorder occurs as a result of poor maladaptive coping skills, early deprivation and serious illness requiring extensive medical care in childhood. ${ }^{3}$ Usually, the patient's primary goal is to receive medical, surgical or psychiatric care to gratify some unconscious psychological needs. Due to diagnostic difficulties, only the most severe cases of factitious disorder are diagnosed correctly, whereas many other cases were missed and treated based on feigned symptoms. ${ }^{4}$ The study of factitious disorder presenting as a Parkinson's and depressive symptoms (DSMIV-TR $)^{5}$ is negligible or nil in India, since these cases are often missing from diagnosis in medical practice due to the busy schedule of neurologist leads factitious to become chronic and difficult to treat.

Financial or Other, Competing Interest: None.

Submission 15-09-2016, Peer Review 25-11-2016,

Acceptance 01-12-2016, Published 08-12-2016.

Corresponding Author:

Dr. Bhuvana C. Revappala,

Consultant Psychiatrist,

Wellspring Mind Care,

Sharavathinagara, Shimoga.

E-mail:doc.barbie@yahoo.in

DOI: $10.14260 /$ jemds/2016/1633

\section{CASE REPORT}

A 52 years old female, married, high school teacher by profession, presented with chief complaints of slowness of all voluntary movements, inability to stand unaided, dizziness, slurred speech, crying spells, small handwriting, etc. since 5 years. Her elder sibling has revealed that she expressed her as having all the nine depressive features out of twelve symptoms that was given in the magazine and forced her to take for psychiatric consultation. However, during the interview these were not her major complaints. She said that she had Parkinson's disorder diagnosed by the neurologists on medication with Tab. Levodopa. But when HAM-D scale was applied, she revealed most of the symptom domains and diagnosed as Parkinson's disorder with depressive symptoms and Tab. Escitalopram $10 \mathrm{mg}$ was added.

She was referred to the two distinct Neurology Clinics for her Parkinson's condition. MRI and EEG done by them were normal. They partially suspected of having Parkinson's disorder and advised to continue the same medications on her last referral to a neurologist.

During a follow-up visit, she revealed of non-compliance with medications since 5 years including antidepressant drug. Further evaluation has found that she has undergone several repetitive investigations in the past. All reports were within normal range. She had also received treatment from alternative medicines and numerous faith healers. She wants to consult various doctors with less experienced or junior doctors at least once a week, was expecting for the detailed physical examination to be done each time, used to force them to prescribe blood investigations, various other procedures like ECT, X-Ray, Hypnosis, etc. argues with them regarding diagnosis, based on the medical knowledge gained from the health magazines and internet articles. Elder sibling informed that she was resisting her husband from meeting psychiatrist, reason was not known to her. She says that her husband and daughter are ignorant of her condition. She has overvalued ideas about health issues and treatment, but she did not have 
overvalued ideas about the misdiagnosis and false treatment that will affect her health.

She was admitted in our hospital for further evaluation where she agreed eagerly. Detailed psychiatric evaluation has done during the hospital stay. The patient belongs to a nuclear middle class family, $3^{\text {rd }}$ child among 4 children with family background of many of her close relatives are doctors. Both parents died due to medical and surgical complications, and her elder brother died 2 years back due to massive brain haemorrhage. There is no family history of any psychiatric illness or substance abuse. Past history of chronic bilateral hearing impairment during childhood for 12 years due to CSOM was depending on family members to interact with other people, had undergone surgery of one ear at the age of 22 years, other ear left untreated. She also had total hysterectomy with bilateral oophorectomy at the age of 42 years for having large fibroid.

Pre-morbidly, as per her elder sibling she is an anxious and easily prone to crying spells on trivial matters, used to get frequent reassurances from family members, always have day dreaming, less physical activities, most of the time stays in her own world, is intensely jealous of others; frequent lying, lacking of empathy and feeling for others, manipulates others by good social skills, argumentative behaviour, expects superior treatment from others, frequent change of job. Her husband reports that she avoids expressing any angry or arguments with her closed ones, because of fear of loss of support or approval from them. She feels uncomfortable or helpless when alone, and she calls more than 5 times per hour to her husband's mobile as she is unrealistically preoccupied with fears of being left alone.

Husband revealed that her symptoms have begun following the successive death of mother-in-law and mother, who were listening and fulfilling her wishes; daughter's irresponsible behaviour and scored very less marks in PUC. After a year of illness she left a job by herself due to her problem with professional life where she was assaulting physically and verbally to her students and their parents complained about her to higher authority. But she did lie to her family members saying that her school is closing permanently. She would force for nurturing care by close family members, even from old age people; would want the people to carry her to the toilet, to correct her sitting posture, while doing so she would make sounds as if it is paining even though there was no pain. She would fall repeatedly on the floor, swinging her both shoulders joint to and fro when facing stress. For the past 2 years she sits or lie over the bed for a prolonged time by holding extremities in a dependent and immobile state with toes tightly flexible above the level of the floor.

During hospitalisation, the patient was willing to talk about her physical illness. She did not exhibit any clear attention seeking, anxious or depressive behaviour since she was an inconsistent and a misleading informant. However, she revealed that she depends on others to take even small decisions of her life. At some point during interview we analysed that she can adopt submissive and inferior role well and has a deep crush with elder brother-in-law where it was not there for him. She refused to sit, stand or walk on the pretext of being weak.

Investigations like LFT, RFT, S. electrolytes, Bone Density Test, Nerve Conduction Test and EEG are done during the hospital stay. All were within normal range including MRI of brain and pelvic scan for urinary incontinence. GPE reveals all her vitals are normal, B/L foot swelling was present due to prolonged holding of extremities in immobile state above the level of the floor. She was trying to feign rigidity of wrist joint by holding wrist joint tightly while examining; no tremor or no micrographia was noted. CNS examination including muscle tones, power, pulling test and balance test were normal. MMSE $^{6}$ and cognitive test was completely normal.

During interview patient was sitting comfortably on a chair, leaned forward, holding both of her upper extremities on the table as if eager to grasp questions and to answer, showed all the facial expressions and bodily gestures during the interview. If the tests were given to her, she was questioning back the doctor about the indication and result finding of the test before doing this. When an attempt was made for her to understand that in spite of her longstanding complaints, the physical investigations were normal and hence there were no major or serious physical disorders. At this point she started to show clear dissociative symptoms in the form of dizziness, exaggerated arm swinging and become uncooperative for any further psychiatric interview. The patient and her family demanded discharge against medical advice. The case has been diagnosed as "factitious disorder by self" (DSM-IV) ${ }^{7}$ presenting as physical (Parkinson's) and psychological (Psychological) along with co-existing histrionic and dependent personality disorder with dissociative symptoms. Thereafter, she was sent home and advised to take clonazepam $0.25 \mathrm{mg}$ TID along with Tab. Nexito $10 \mathrm{mg}$ OD and advised to come for followup for therapy section. But unfortunately, she did not come for followup.

\section{DISCUSSION}

The patient was diagnosed as factitious disorder because of her symptom presentation, which were like 'textbook case presentations' with full symptom findings and medical terms, excessive exploration of medical knowledge, unusual grasping of medical terms during the interview, non-compliance with anti-Parkinson's drugs, relieving of symptoms during physical examination, the discrepancy between clinical and laboratory (EEG) findings. Although, abnormal MRI and EEG findings is not a certain necessity for the diagnosis of Parkinson's disorder, her continuous visits to different doctors and her chronic physical illness during childhood including premorbid personality profile which can precipitate factitious disorder. Despite having severe psychiatric symptoms, she was reckless about her symptoms. It can be differentiated from malingering, where patient is intentionally faking or creating illness in order to obtain secondary gain (e.g. workers' compensation, disability payments, avoiding work or jail time, pain medication, etc.). ${ }^{8}$

Bradykinesia among patients with Parkinson's disease seem to run down either in speed or amplitude of movement with successive movements without anybody's support during mild-to-moderate stage of illness. ${ }^{9}$ Speech abnormalities might be seen, but these have been inconsistent in nature, precipitates only when anxious. Urinary incontinence can be due to removal of uterus leading to poor muscle support and she in menopause. Her intermittent normal walking makes most neurologists to decide that this can be due to on and off phenomenon of the drug dopamine. But on careful evaluation, these feigning and dissociative symptoms were only during trivial stress factors. 
Since her duration of illness is from 5 - 6 years, her clinical description of symptoms makes us to diagnose the advanced stage of Parkinson's disorder, but her cognitive tests were completely normal. She still manipulates, argues and has all the facial expressions while interacting. In general, it takes more than 15 - 20 years to reach the advanced stage of Parkinson's and it will be usually associated with moderate-tosevere cognitive impairment due to an associated brain damage. This inconsistent finding makes us a diagnostic clue of factitious disorder.

A study by Vingerhoets $\mathrm{G}^{10}$ has reports of having a greater risk of cognitive dysfunction in Parkinson's disease patients with predominant akinesia/rigidity, tremor at onset may be a marker for more widespread brain pathology that contributes to an increased risk of cognitive impairment.

Another study by Bauer $\mathrm{M}$ et al2 five of 1538 (0.3\%) patients were diagnosed as having factitious disorder with feigning of neurological syndromes. Their study has concluded that factitious disorder presenting with neurological syndromes may be more prevalent than generally assumed and confirmed the idea of frequent coincidence of factitious and personality disorders, which is similar to our study findings.

Patients with FD present a challenging treatment problem. Treatment can include double-blind technique, face-saving behavioural strategies, treatment of underlying axis I and axis II disorders, appoint a primary care provider for all medical and psychiatric treatment who is a gate keeper. Another important issue in management involves the therapist's own counter-transference reactions. ${ }^{3}$

The key to successful management requires negotiation and agreement of the diagnosis with the patient and engagement of that patient with treatment. No robust research evidence is available to support the effectiveness of a management strategy (long-term psychotherapy) for factitious illness.

Recovery from chronic factitious disorder is rare and largely unknown, because many patients understandably drop out of followup. A study by Krahn LE 11 showed that threequarters of the patients were confronted, but only one in six acknowledged that their illness was self-induced; $12 \%$ agreed to have psychiatric treatment, but the outcomes were not published.

\section{CONCLUSION}

- Factitious disorder remains highly under-diagnosed in developing countries like India. Mental health professionals need to be more aware and inquisitive about this particular disorder, so that they do not miss the diagnosis.

- Indeed, factitious disorders can be exasperating to the physician and treatment team, as patients with these disorders consume valuable time, resources and energy. However, a deeper understanding of this disorder reveals that patients are powerfully compelled to appear ill and have little insight into their behaviours.

- The clinical presentations of persons with factitious disorder are varied and impact every areas of treatment. The main treatment goals for these disorders are to minimise harm to the patient and drain on health care resources.

\section{REFERENCES}

1 Grover S, Kumar S, Mattoo SK, et al. Factitious schizophrenia. Indian J Psychiatry 2005;47(3):169-72.

2 Bauer M, Boegner F. Neurological syndromes in factitious disorder. J Nerv Ment Dis 1996;184(5):281-8.

3 Kaplon, Sadock. Comprehensive textbook of psychiatry. 2008;1:1479-89.

4 Mishra PB, Shyangwa P, Khandelwa SK, et al. Factitious disorder with Oligoanuria: a case report. Indian Journal of Psychiatry 1999;41(4):374-6.

5 American Psychiatric Association. Diagnostic and statistical manual of mental disorders. $4^{\text {th }}$ edn. (DSM-IV). Washington, DC: APA 1994.

6 Folstein MF, Folstein SE, McHugh PR. Mini-mental state. A practical method for grading the cognitive state of patients for the clinician. Journal of Psychiatric Research 1975;12(3);189-98.

7 American Psychiatric Association. Diagnostic and statistical manual of mental disorders. $5^{\text {th }}$ edn. (DSM-V). Washington, DC: APA 2013.

8 Bass C, Halligan P. Factitious disorders and malingering: challenges for clinical assessment and management. Lancet 2014;383(9926):1422-32.

9 Hallett M. Psychogenic parkinsonism. J Neurol Sci 2011;310(1-2):163-5.

10 Vingerhoets G, Verleden S, Santens P, et al. Predictors of cognitive impairment in advanced Parkinson's disease. J Neurol Neurosurg Psychiatry 2003;74:793-6.

11 Krahn LE, Li H, O'Connor MK. Patients who strive to be ill: factitious disorder with physical symptoms. Am J Psychiatry 2003;160(6):1163-8. 